\begin{tabular}{|c|c|c|c|}
\hline$\prod_{\text {INESEG }}^{\text {INTERNATIONAL }}$ & $\begin{array}{r}\text { International } \\
\text { Res } \\
w w v\end{array}$ & $\begin{array}{l}\text { urnal of Health Services } \\
\text { rch and Policy } \\
\text { rgipark.org.tr/ijhsrp }\end{array}$ & \\
\hline $\begin{array}{c}\text { SCIENCE AND } \\
\text { EDUCATION GROUP }\end{array}$ & e-ISSN: 2602-3482 & DOI:10.23884/ijhsrp.2019.4.3.08 & IJHSRP \\
\hline
\end{tabular}

\title{
SUSTAINABILITY, EQUITY AND EFFECTIVENESS IN PUBLIC FINANCING FOR HEALTH IN UGANDA: AN ASSESSMENT OF MATERNAL AND CHILD HEALTH SERVICES
}

\author{
*Vincent Okungu ${ }^{1,2}$ iD , Marshal Mweu (iD 1, Janine Mans $^{3}$ iD \\ ${ }^{1}$ School of Public Health, University of Nairobi; ${ }^{2}$ Philips East Africa \\ ${ }^{1}$ School of Public Health, University of Nairobi \\ ${ }^{3}$ Nathan Associates, Inc. \\ *Corresponding author: okungu008@gmail.com
}

\begin{abstract}
This assessment aimed to understand whether financing for maternal, child health and immunization services are sustainable, efficient, effective and equitable. Data sources included various national and international reports related to financing maternal and child health services. The results show that funding for maternal and child health $(\mathrm{MCH})$ services are unsustainable over the long term because the main financing source is out-of-pocket (67\% of the total for MCH). However, Uganda shows higher efficiency in delivery as it has the lowest average cost per delivery (USD 50) compared to USD 70 (Kenya) and USD 95 (Ghana). Overall, MCH interventions being financed show some levels of effectiveness; e.g. maternal mortality rates dropped from 420/100000 live births in 2010 to 343/100000 live births in 2016; under-5 mortality rates reduced from 151/1000 live births in 2000 to 64/1000 live births in 2016. There are, however, inequities by region, age, education status and wealth index; e.g. $37 \%$ in the poorest quintile have unmet family planning needs compared to only $23 \%$ in the wealthiest quintile. In conclusion, public financing for primary services such as MCH requires reforms to strengthen health sector performance. The reforms should address sustainable financing, efficiency, effectiveness, and equity in service delivery.
\end{abstract}

Keywords: Maternal Child Health, Public Finance, Uganda

Received: June11, 2019

Accepted: October 6, 2019

\section{Introduction}

Uganda's population is estimated at about 40 million people as of 2017 and growing at more than $3 \%$ per annum[1]. The high annual growth rate is attributed to the high total fertility rate of over six children per woman observed for the last four decades against the backdrop of declining mortality rates. By 2020, women within the reproductive age bracket (15-49 years of age) will constitute about $20 \%$ of Uganda's total population and an equal proportion is children below the age of five years[2].

Currently, Uganda has the highest proportion of young people in the world, with more than half (57\%) of Uganda's population under the age of 18 years. The population trends and structure result in high demand for maternal and child health services including immunization; efforts should focus on ensuring that the demand for these services is equitably met at all levels nationwide.

The ongoing transformation of the Ugandan health sector is meant to improve access to quality services for all with a focus on primary health care. However, the groundwork for the transformation of the health sector has not been effectively financed; e.g., recent rapid growth in government expenditure 
between FY 2012/13 and FY 2016/17 has not benefited the health sector proportionally. Overall, the health sector received only $6 \%$ of the total share compared to other sectors such as Works and Transport (21\%), Education (13\%) and Justice, Law and Order (10\%)[3]. The health sector has not been given the priority it deserves even with the evidence of the growing burden of communicable and noncommunicable diseases (NCDs).

Specifically, the global burden of disease (2016) shows that maternal and neonatal health conditions contribute about 22 percent of years of life lost (YLL) in Uganda[4]. To address the public health burden resulting from maternal and child health conditions, the MOH has defined strategic policy goals to achieve the longer-term Sustainable Development Goal (SDG) targets by 2030. The highlights of the strategic policy goals include addressing the main causes of maternal deaths; ending preventable newborn and under-5 mortalities through improvement of immunization coverage and timely access to health care; improving adolescent health by making efforts to control teenage pregnancies, child marriages and scaling up contraceptive use, and working toward universal health coverage (UHC). To support this ambitious agenda, Uganda is planning to establish a National Health Insurance Scheme and promote voucher programs to increase demand-side financing for the use of family planning and safe motherhood services by the poor[5]. Also, the Uganda National Expanded Program on Immunization (UNEPI) supports routine immunization services to accelerate the control or elimination of vaccinepreventable diseases, surveillance and outbreak response, and introduction of new vaccines. Current efforts under the Comprehensive EPI Multi-Year Plan (cMYP) 2016- 2020 aims to sustain gains on DPT immunization, introduce new vaccines, and strengthen microplanning and implementation of the Reach Every District/Reach Every Child (RED/REC) strategy in all districts, as well as improving overall program management of EPI at all levels[6]. The national immunization coordination committee (NICC) is expected to play a critical role in ensuring the success of immunization programs. The country has achieved significant increases in numbers of children immunized with a reported $6.6 \%$ increase in total immunization between 2014 and 2018[7].

The political will to improve immunization coverage and safeguard child survival is evident when in 2016 Parliament passed the Immunization Act, which provides for compulsory immunization of children, women of reproductive age and other target groups against vaccine-preventable diseases. Uganda is yet to reach the immunization coverage target of $80 \%$ of the target populations but has partnered with the Global Alliance for Vaccines and Immunization (GAVI) and other development partners to introduce new vaccines, such as the pneumococcal conjugate vaccine (PCV) and the human papillomavirus (HPV), as part of the strategy to reach immunization targets. Going forward, GOU is working to introduce the new rotavirus vaccine, the yellow fever vaccine, the MenA vaccine, and the inactivated polio vaccine (IPV).

Overall, Uganda has made little progress toward improving the health of mothers and children; the country still ranks among the top 10 countries in the world with high maternal, newborn and child mortality rates[8]. The country has poor reproductive, maternal, neonatal, child and adolescent health (RMNCAH) indicators. Neonatal mortality rate (NMR) has remained stagnant for the last decade though maternal mortality rate (MMR) and child mortality trends show important reductions. About $20 \%$ of Ugandans live below the poverty line as of 2013[1,9] and this could be a contributing factor toward the relatively poor MCH indicators. The Health Sector Development Plan (HSDP) 2015/16 - 2019/20, prioritizes improvements in $\mathrm{MCH}$ indicators and recognizes among other factors, poor policy implementation as the main contributor to the high mortalities. The Sharpened Plan (2016 - 2020), a 
component of the HSDP, specifies the strategies to be used to accelerate progress towards improving $\mathrm{MCH}$ indicators. The plan focuses on strengthening the national health service delivery system and prioritization of a package of technical interventions and strategies that will realize the largest health impact for the country based on the latest evidence on effectiveness[5]. Part of the plan to The multifaceted approach to immunization in Uganda is an example of a plan to improve service delivery systems. The Mother and Child Survival Program (MCSP), the Stronger Systems for Routine Immunization (SS4RI), the Uganda Muslim Medical Bureau (UMMB) and the Ministry of Health through the Expanded Program on Immunization (UNEPI), are among the key players that are involved in the expansion of immunization coverage to reach every child with immunization services that are effective, safe, responsive to community needs and are sustainable. MCSP, in particular, has introduced the Reach Every Child (REC)- QI approach as part of its global innovations and learning agenda to improve immunization coverage and effectiveness [10]. With a focus on public financing, the study aimed to assess whether Uganda's financing for maternal and child health services is sustainable, efficient, effective and equitable.

\section{Methods}

This study derives its information in two main ways. First, as part of a public expenditure review (PER) for Uganda's Ministry of Health, conducted with funding from USAID, we looked at various national and international documents related to financing health care generally and specifically financing for maternal and child health services, and immunization. Second, we analyzed documents containing indicators for maternal and child health services and immunization and assessed their correlations with financing trends in terms of sustainability, efficiency, equity, and effectiveness. The exercise took place from December 2017 to June 2018. Data search and collection was largely targeted, i.e. we specifically sought online and hard-copy documents on $\mathrm{MCH}$ and immunization financing and indicators from the Ministry of Health (MOH)- Uganda, the Uganda Bureau of Statistics (UBOS) and organizations such as the World Health Organization (WHO), the World Bank and GAVI. Uganda's health management information system (HMIS) also provided considerable data to inform our analysis.

Key government documents considered in the analysis included the National Development Plan (I \& II), various national health accounts (NHAs), national demographic health surveys (DHS), among other reports specific to $\mathrm{MCH}$ and immunization. These plus other technical reports and documents were obtained both directly from MOH counterparts and indirectly through online sources. A few additional documents were retrieved through Google search, which included regional and global reports as well as peer-reviewed journal articles specific to $\mathrm{MCH}$ and immunization in Uganda. A combination of search terms used included "maternal health financing Uganda"; "maternal child health budget Uganda)"; "maternal child health indicators Uganda"; and maternal mortality Uganda".

The analysis was mainly descriptive and involved looking at trends in budgetary allocations and financing of maternal and child health programs as well as immunization, and making correlations and inferences concerning sustainability, efficiency, effectiveness, and equity. Findings were peer-reviewed by senior officials from the Ministry of Health $(\mathrm{MOH})$, officers from the United States Agency for International Development (USAID) and the World Bank.

\section{Ethical approval}

Secondary data sources were used in the article so no ethical approval was required. 


\section{Results}

\subsection{Financing trend and sustainability}

There is an upward trend in maternal and child health $(\mathrm{MCH})$ financing in Uganda. For $\mathrm{MCH}$, the proportion of spending increased from FY 2012/13 to FY 2015/16[11, 12]. Overall, MCH services received $16.2 \%$ of government funds for health programs, trailing only HIV/AIDS (21.9\%) and oral health conditions under NCDs (17.2\%), and exceeding malaria (11.9\%). However, in terms of total health spending on $\mathrm{MCH}$ issues, households (private sources) bear the greatest burden because the majority of the funds is paid out-of-pocket (Table 1).

Table 1. Spending on Maternal and child health, average FY2015/16)

\begin{tabular}{|l|c|c|c|c|c|c|c|}
\hline \multirow{2}{*}{} & \multicolumn{2}{|c|}{ Private } & \multicolumn{2}{c|}{ Public } & \multicolumn{2}{c|}{$\begin{array}{c}\text { Development } \\
\text { Partners }\end{array}$} & Total \\
\cline { 2 - 8 } & $\begin{array}{c}\text { USD } \\
\text { Millions }\end{array}$ & $\%$ & $\begin{array}{c}\text { USD } \\
\text { Millions }\end{array}$ & $\%$ & $\begin{array}{c}\text { USD } \\
\text { Millions }\end{array}$ & $\%$ & $\begin{array}{c}\text { USD } \\
\text { Millions }\end{array}$ \\
\hline Maternal conditions & 67.77 & 66.52 & 19.60 & 19.24 & 14.52 & 14.25 & 101.89 \\
\hline Perinatal conditions & 48.40 & 77.76 & 8.08 & 12.97 & 5.77 & 9.27 & 62.25 \\
\hline Family planning & 0.001 & 0.01 & 3.11 & 19.51 & 12.82 & 80.48 & 15.92 \\
\hline $\begin{array}{l}\text { Other reproductive health } \\
\text { (n.e.c.) }\end{array}$ & 0.001 & 0.01 & 4.54 & 46.70 & 5.18 & 53.29 & 9.72 \\
\hline \multicolumn{1}{c|}{ TOTAL } & $\mathbf{1 4 0 . 1 6}$ & $\mathbf{6 7 \%}$ & $\mathbf{3 5 . 3 2}$ & $\mathbf{1 7 \%}$ & $\mathbf{3 2 . 8 2}$ & $\mathbf{1 6 \%}$ & $\mathbf{2 0 8 . 3 0}$ \\
\hline
\end{tabular}

Financing health care primarily through out-of-pocket is highly inequitable as the cost burden is borne by individual households. However, the immunization program in Uganda is largely donor-driven with reports from GAVI [13] indicating that external resources accounted for about $81 \%$ of total funding.

\subsection{Efficiency}

While unit costs are not available across the full range of $\mathrm{MCH}$ services, analysis of facility-level data on the costs of delivery demonstrates a wide variety of costs. Overall, Uganda is one of the countries in sub-Saharan Africa with a relatively lower average cost of delivery (Figure 1)[14]. The average cost of birth varies greatly by the type of health facility. This difference may be due to a range of issues; e.g., hospitals may tend to attract more complicated births due to higher caliber staff and equipment, leading to higher average costs. There may be also lessons that can be learned on more routine deliveries, e.g., those related to the greater reliance on midwives in health facilities tend to have lower costs. 


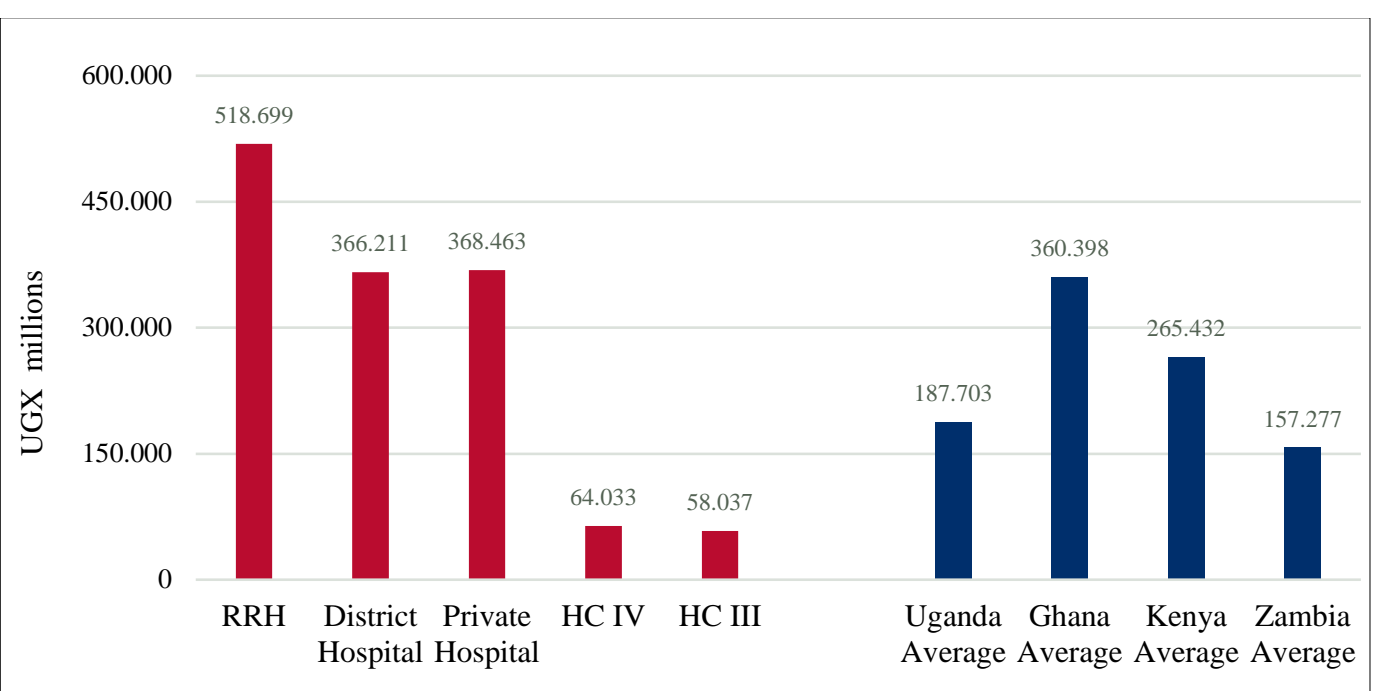

Figure 1. The average cost of delivery - by facility type and across comparator countries (UGX) Note: All data is for 2011 except Zambia, which is for 2010

Health provider costs as shown reflect different mixes of staff and medications and other material, as well as different staffing patterns. The two mission health facilities had higher material costs than the two public health facilities, while the public hospital has higher personnel costs for four of the six services. In contrast, the mission health center had higher labor costs than the public health center for all three services the center provided. Reflecting differences in utilization levels in relation to staffing, midwives at the mission hospital delivered more babies per year on average (68 deliveries per year) than at the public hospital (39 per year). Public health center midwives delivered the most babies per year (116 per year per midwife) followed by private midwives (108 per year). Most international standards suggest that a nurse midwife could perform 15 to 20 births per month, or 180 to 240 births per year, though an additional midwife would be needed in a facility setting to cover for leave time and women needing services at the same time[15].

The costing analysis estimated the additional costs in 2016 - 2020 of increasing access to the MCH priority packages in Uganda to be US\$ 274 million, including systems investments. While costs vary depending on packages and delivery levels, estimates show that the average additional per capita investments per year are US\$ 0.70, US\$ 4.69, and US\$1.69 for the core, expanded and comprehensive packages respectively.

\subsection{Effectiveness}

Recent data show improvements in maternal and child mortality rates which suggests that $\mathrm{MCH}$ interventions have been relatively effective even if not at the levels expected (Figure 2). 
Figure 2a. Maternal deaths per 100,000 live births

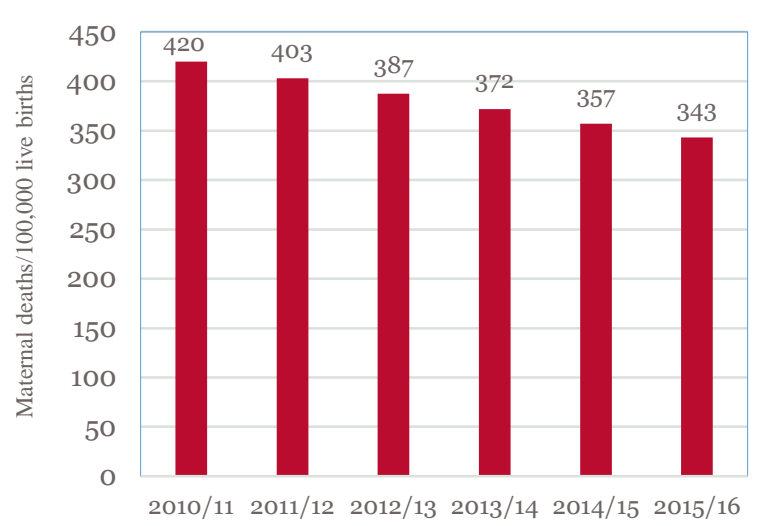

Figure 2b. Reductions in child mortality (deaths per 1,000 live births)

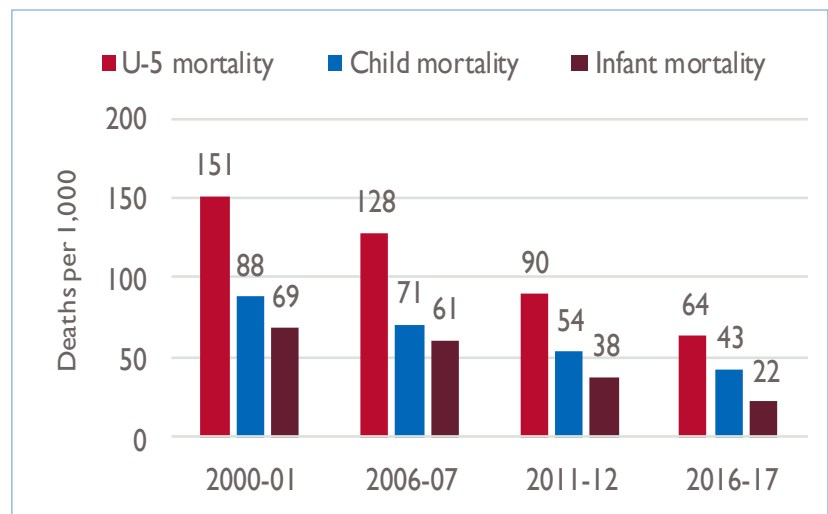

Figure 2. Maternal and child health in Uganda

As Figure 2 shows, there are significant improvements in under-5 (U-5) and child mortality rates; however, maternal mortality per 100,000 live births has remained stubbornly high even though there were some improvements in the period 2010 to 2016. More strategic interventions including increased financing for maternal and child health services from a prepaid pool of funds are required to rapidly lower MMR in Uganda to reach SDG targets.

Further scrutiny suggests that the full impact of maternal and child health interventions may be limited due to the lack of appropriate equipment and materials at the facility level. The 2012 ABCE survey [14] found that only $13 \%$ of the facilities in the sample reported having the full stock of medications, tests, and medical equipment recommended for the provision of ANC. Less than five percent of health centers (HCs) were fully equipped to provide ANC. For deliveries, less than $10 \%$ of all facilities were fully equipped for routine deliveries, and many lower-level facilities do not offer emergency obstetric services (Figure 3).

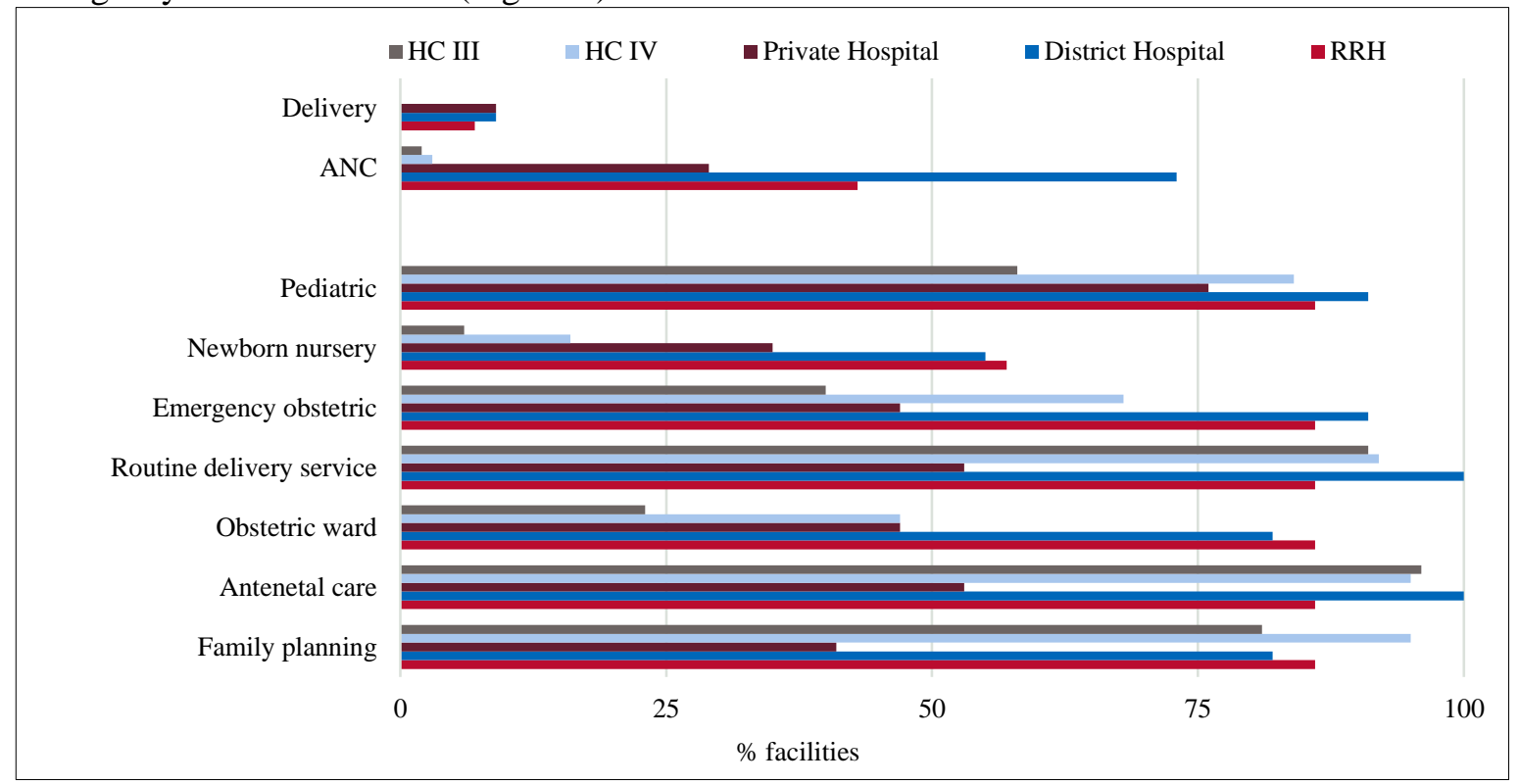

Figure 3. Availability of facilities and equipment for maternal and child health services 
On the other hand, the expansion of vaccine coverage has a clear relationship with funding levels (Figure 4). The increase in funding in 2013/14 had a clear impact on increased immunization coverage in the following year and the dip in funding in FY2014/15 appears to have yielded a lower average coverage rate the following year. This indicates that overall spending appears to be well-targeted. A key challenge in immunization seems to be in maintaining a linear progression in coverage (Figures 4), which could be partially linked to inconsistency in financing.

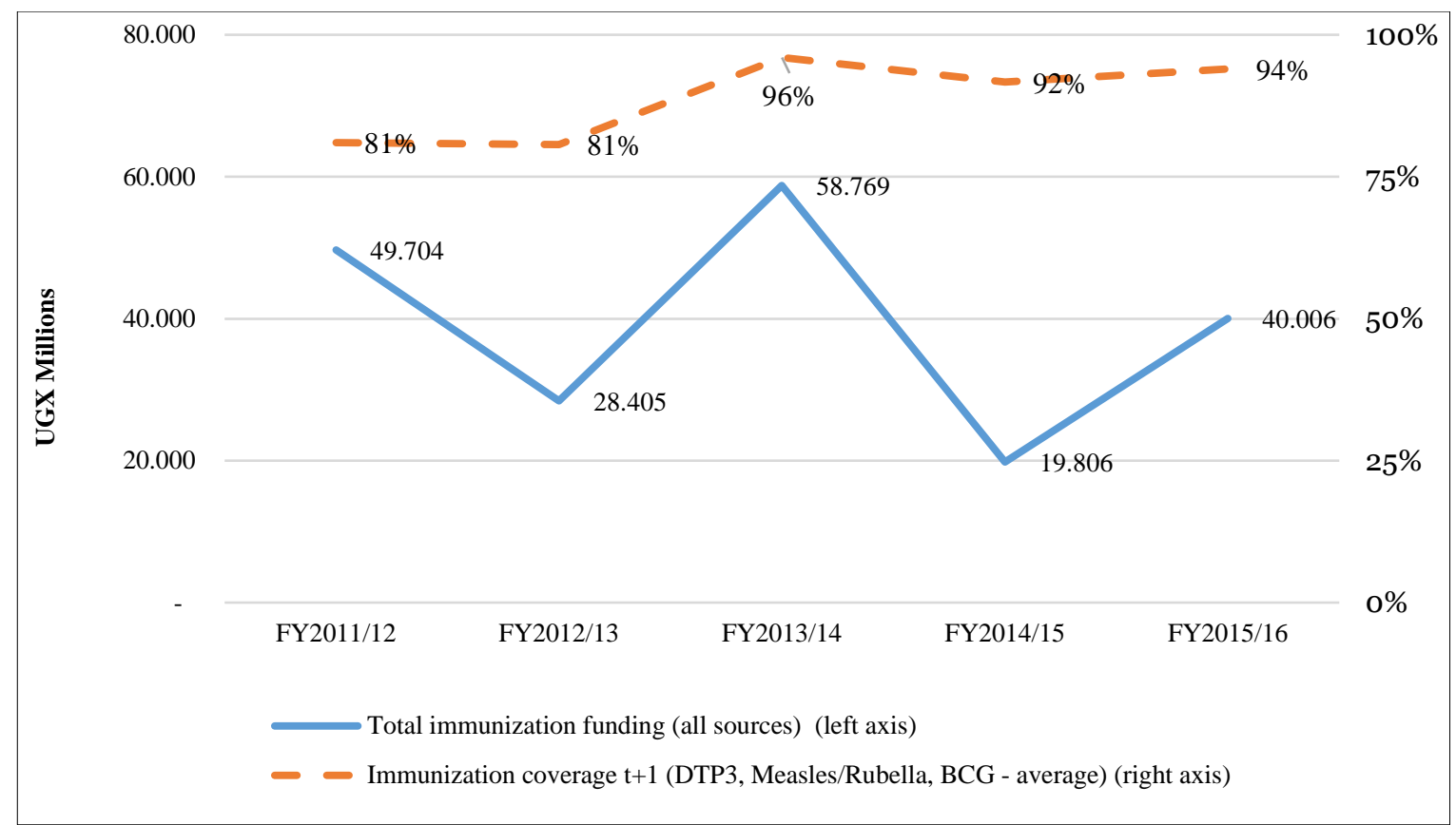

Figure 4. Trends in immunization spending and vaccine coverage (year $\mathrm{t}+1$ )

Source: National Health Accounts (NHA) 2011/12. 2013/14, 2015/16; World Health Organization (WHO) Country reported immunization data

\subsection{Equity}

Indicators for both maternal and child health programs and immunization interventions register levels of inequity. For example, although maternal and child health indicators have been improving steadily in Uganda, there is unequal distribution in these improvements by location and wealth status. Rural areas, for example, report poorer maternal health service use indicators than urban areas, which could be linked to various dimensions of access to maternal health services including affordability[16]. The DHS 2015/16 data indicate that the gap in access appears to be largest with respect to skilled deliveries and/or at a health facility[17] (Figure 5). 


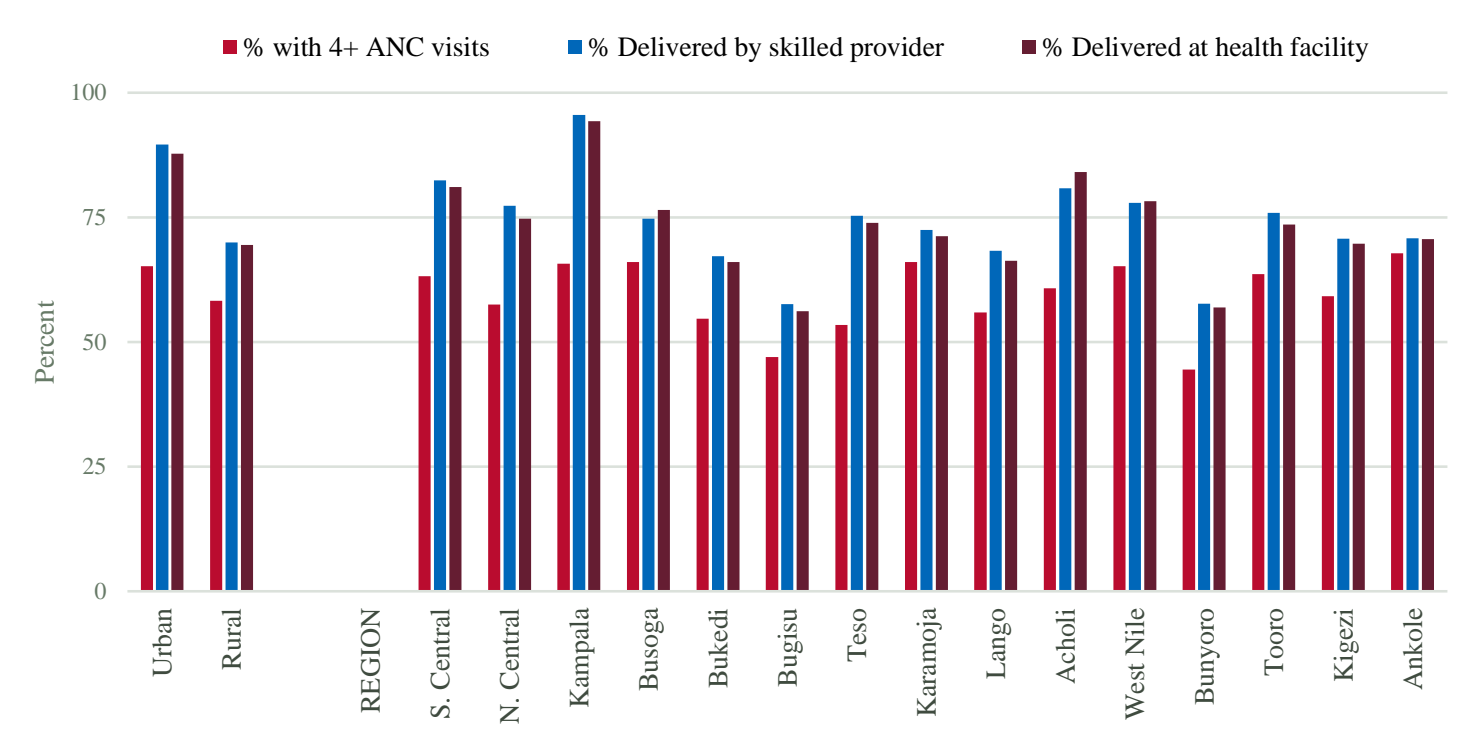

Figure 5. Percent of women who had a live birth in the 5 years preceding Demographic Health Survey (DHS) 2016 survey using maternal health services

Regionally, the Bugisu and Bunyoro perform below $60 \%$ in all maternal health indicators even though they are not the poorest regions, suggesting other factors apart from poverty have a role in the existing inequities in maternal health outcomes. Inequities also exist between the rich and poor; e.g. about $66 \%$ of women in the highest quartile who had a live birth attended all four ANC visits compared to $54 \%$ of women from the poorest quartile. Also, about $93 \%$ of the wealthiest households had a delivery at a health facility compared to $64 \%$ of the poorest quartile. There are also marked differences in unmet family planning needs by all parameters (Figure 6). Unmet family planning needs have implications on maternal health outcomes and child survival. Rural area residents have higher unmet needs than their urban counterparts indicating poorer maternal and child health outcomes in rural than urban areas. Overall, the poorest households reported unmet FP needs at 37\% compared to about $22 \%$ in the richest households. This disparity is not evenly felt, however. Karamoja has the lowest unmet needs (about $20 \%$ ) even though it is one of the poorest regions in Uganda, while West Nile (43\%) and Busoga (about $37 \%$ ) have the highest unmet needs. 


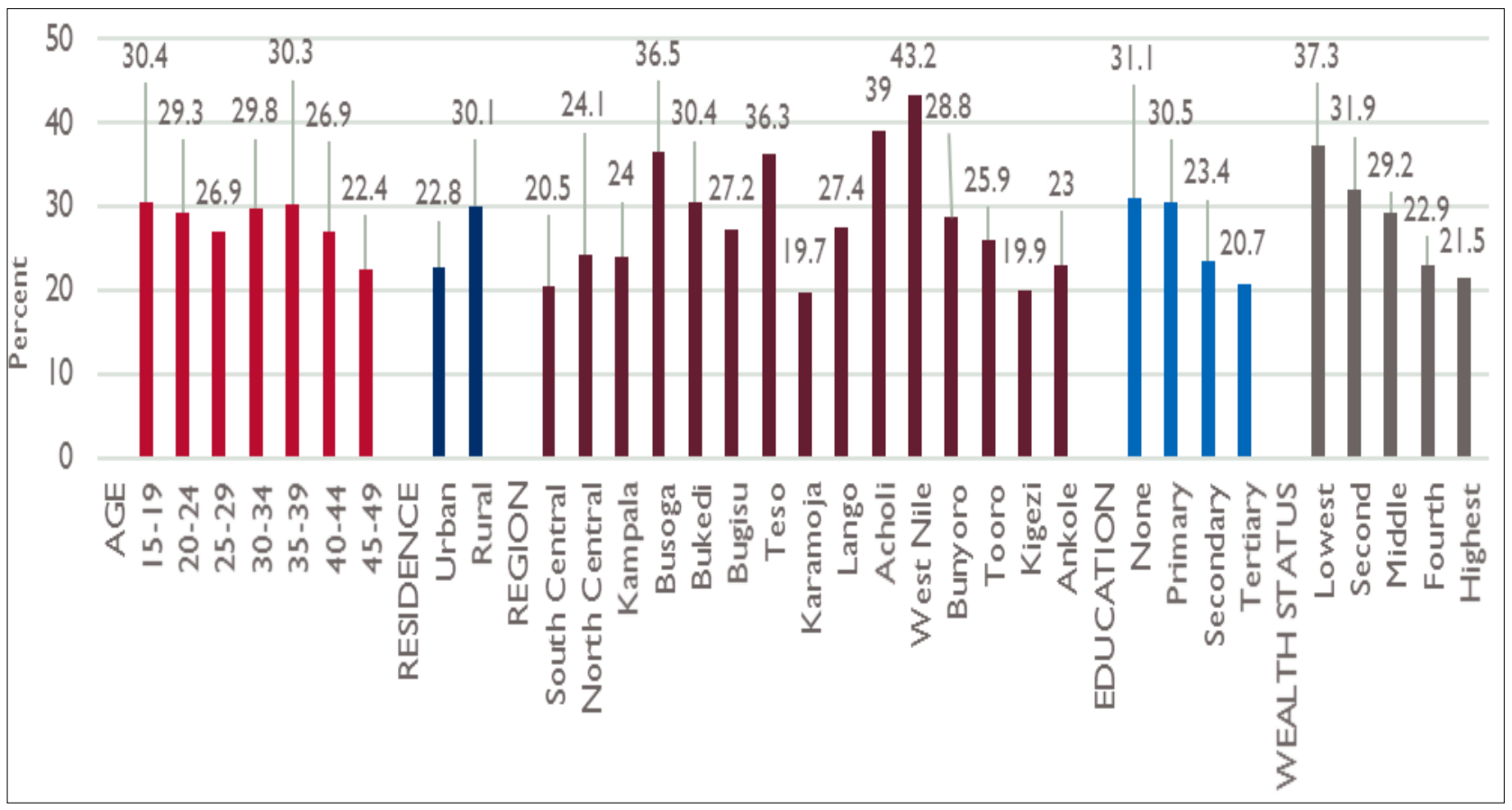

Figure 6. Percent of population with unmet family planning needs by category

Source: Demographic and Health Survey (DHS) 2015/16

Inequities are also evident in vaccine coverage. Vaccination is a key ingredient in child health but differences in coverage are reported in terms of gender, residence (rural vs. urban), regions and level of education. There has been progressing in filling these equity gaps which could be linked to various factors including better targeting as well as the focus on rural and hard to reach populations, e.g. in Karamoja. The fact that vaccines are fully subsidized therefore poses no financial barriers to access is another important factor. The best performing region in terms of overall vaccine coverage is Karamoja which is one of the poorest regions in Uganda. High vaccine coverage in the poorest region (Karamoja) as well as the fact that coverage is highest in the poorest quintile for basic (56\%) and all-age appropriate vaccinations (41\%) and lowest in the wealthiest quintile (54\% and 40.9\%) respectively (Figure 7), suggests there is no direct link between wealth status and vaccine coverage in Uganda. However, wide variations in coverage still exist regionally and in levels of education which deserve the attention of policymakers. 


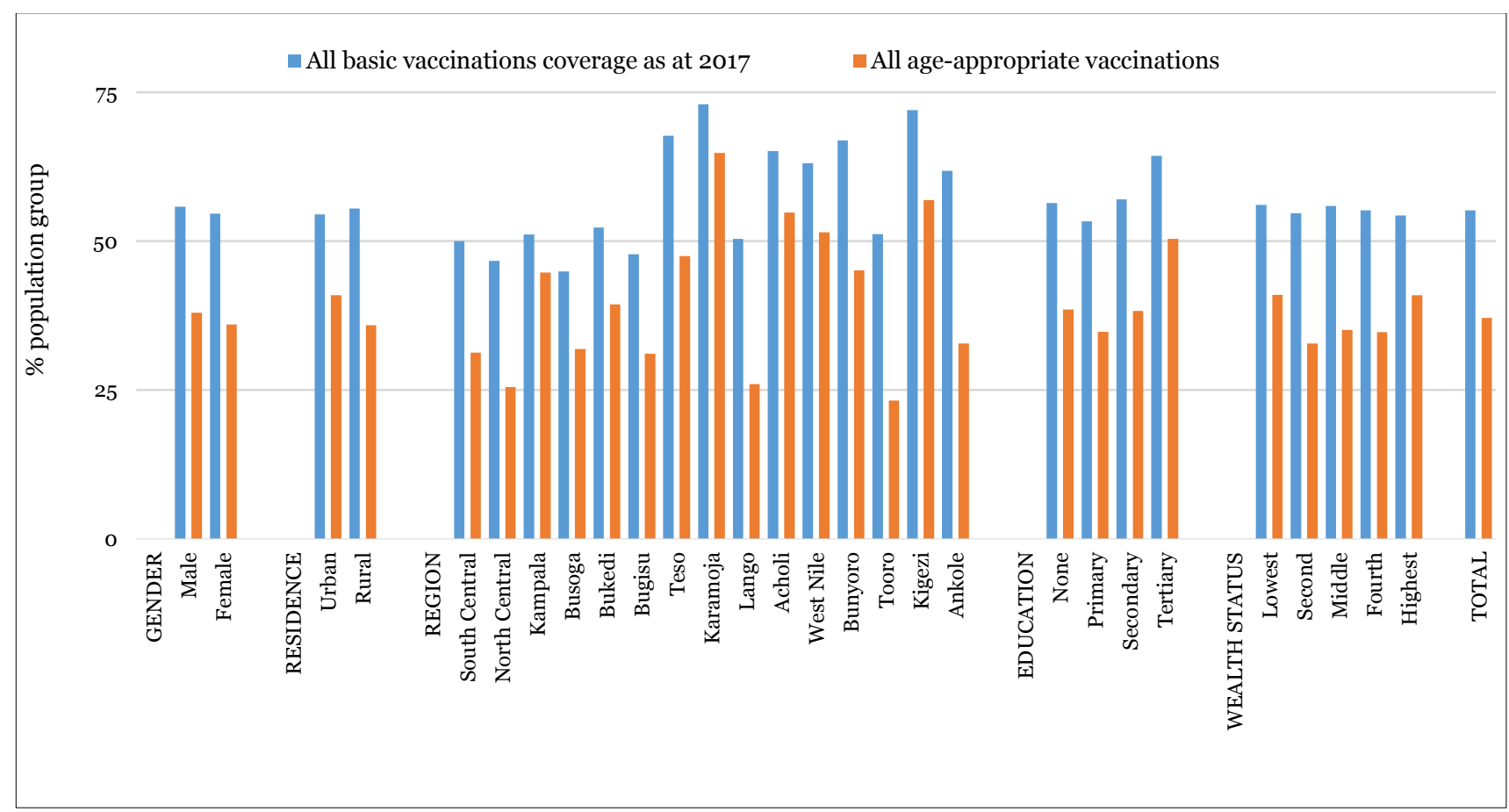

Figure 7. Vaccine coverage by gender, region, education and wealth quintile (percent)

Maternal and child health outcomes are not entirely encouraging but more coordinated efforts from all stakeholders including financing agents and policymakers are required to register rapid progress in $\mathrm{MCH}$ outcomes.

\section{Discussion}

Initiatives to improve $\mathrm{MCH}$ services in Uganda in the past decade have been spearheaded largely by the national Safe Motherhood Program (SMP). The initiatives involve developing networks of traditional birth attendants (TBAs) and interventions to forecast high-risk obstetric events and strengthen referral systems[18]. Despite these and other efforts, Uganda remains one of ten countries globally which contribute the highest maternal, new-born and child mortality rate[2, 5, 18]. The contradiction between the intervention and outcome could be linked partially to the fact that the SMP focused its attention on TBAs even though Uganda has a large shortfall of health workers especially of midwives to deliver a range of life-saving interventions[18]. The government has for several years now frozen recruitment of health workers due to fiscal constraints, which, unfortunately, is a common fiscal practice across the East African region.

The primary focus for Uganda currently is developing a prepaid health system and moving away from reliance on out-of-pocket (OOP) payments to pursue universal health coverage (UHC). The global report on public health expenditure indicates rising domestic sources of funding for health in low- and middle-income countries (LMIC) [19]. As a long-term strategy to address fiscal shortfalls and achieve UHC, there is consensus on the need for LMIC to pursue innovative health financing models, improve efficiency in the use of existing resources and increase and sustain domestic financing for health care to reduce donor dependency and OOP payments[20, 21]. Currently, financing for MCH relies largely on OOP payments and donor funding respectively. Existing evidence[22-27] indicates that these types of financing arrangements are both inefficient and unsustainable. OOP payments, in particular, represent 
the worst form of fragmentation; they place the financing burden on individuals and are impoverishing. On the other hand, donor funds are often unpredictable and a lot of its inflow depends on external factors beyond the control of the recipient country. In short, in terms of financing MCH services including immunization in Uganda, a lot still remains to be done to promote sustainability and ensure that interventions are more effective than they are currently. Hence the motivation to be innovative in financing health care to raise more revenue, contain rising health care costs, reduce OOP payments and compensate for the dwindling external funding.

Domestic financing is particularly critical in consolidating the gains already made in reducing maternal and child mortality. Currently, financing, especially from the government, is both inadequate and inconsistent for MCH services. Increasing funding from public sources is fundamental and driven by, first, the need to adequately equip all health facilities for at least routine deliveries, and second, the need to implement the recommendations of the Immunization Program Financial Sustainability Plan. However, an increase in funding should be complemented by the efficient use of all available resources. Hence, the government is encouraged to identify and roll-out good practice by health facilities demonstrating a lower cost per dose of delivering vaccines for example, while maintaining delivery models that are appropriate to the demographic group being targeted. Also, continued use of pooled procurement mechanisms for $\mathrm{MCH}$ supplies including vaccines will achieve economies of scale in procurement. Where efficient, there is a need to implement strategies to reduce wastage.

Critical efficiency gains will specifically be realized by expanding the use of cost-efficient service delivery options - such as the use of mid-wives for a routine delivery. Establishing bEmONC ready and accessible facilities at the sub-county level will increase access to quality skilled birth attendance especially for the poor majority. Service delivery improvements at the lower levels will yield returns in terms of system performance at HC IV and hospital levels by reducing patient loads and assisting referral. On the other hand, equipping HC IV and General Hospitals for cEmONC will only make a significant difference if other investments such as effective emergency transport to these facilities and financial or other impediments to their attendance are addressed. Addressing access issues in high burdened urban districts such as Kampala and Wakiso requires providing financial support to the poorest urban families through voucher schemes. This would allow eligible families to access the private sector for quality $\mathrm{MCH}$ services without investing in public sector infrastructure. Of utmost importance is addressing the obvious systemic inefficiencies current in Uganda[28-31]; there is often no guarantee that donor funds for $\mathrm{MCH}$ services do end up in these services due to fungibility in aid[32, 33].

Cultural, geographic and socio-demographic factors seem to be the main drivers of inequity in $\mathrm{MCH}$ services including immunization coverage. There is a clear relationship between maternal and child mortality as well as immunization coverage on the number of antenatal care visits, maternal education, age, area and region of residence[34]. On the whole, the combination of poor financing and a host of socio-demographic factors have clearly contributed to below per outcomes in MCH. For example, in 2016, 41\% of all pregnancies in Uganda were unintended and about $25 \%$ of women in Uganda have had their first child by age 18[34]. These suggest relative ineffectiveness of ongoing maternal health interventions as evidenced by high unmet family planning needs as well as unacceptably high maternal mortality rates. As a signatory to the Global Strategy for Women's and Children's Health, Uganda failed in all its efforts around millennium development goals (MDGs) 4 and 5As of 2011 and, given the current progress rate, shows no signs of achieving the health-related sustainable development goal (SDG) 3 by 2030 . 
In conclusion, Uganda has registered some progress in improving maternal and child outcomes. However, progress remains unacceptably slow such that Uganda remains one of the highest-burden countries globally in terms of maternal health outcomes. The country needs to pull together in addressing maternal and child mortalities by first of all re-prioritizing the health sector in government expenditure and improving the allocation of funds to $\mathrm{MCH}$ and immunization services. Policy reforms to expand domestic resources for health should consider key areas such as efficiency, effectiveness, and equity in service delivery. To address the reported inequities, for example, root-cause analysis of sociodemographic and regional differences in uptake of maternal health and immunization services should be considered. The current focus of MCH efforts in rural areas is commendable but Uganda's urban population is rapidly increasing- depicting a five-fold increase in the last three decades and are increasingly becoming highly burdened. These are factors that should be considered in the design of effective $\mathrm{MCH}$ interventions.

\section{Acknowledgment}

Funding for the project was from USAID and implemented by Nathan Associates, Inc. We thank the following for their participation in the management of the project and data collection: Mr. Enock Mwami, Mr. John Kauta, and Mr. Joseph McGrann.

\section{References}

[1] Government of Uganda, "State of Uganda Population Report 2018: Good Governance- A prerequisite to harness the Demographic Dividend for Sustainable Development " Government of Uganda, Kampala, 2018.

[2] Uganda Bureau of Statistics, "Uganda Demographic and Health Survey," Government of Uganda, Kampala, 2016.

[3] Uganda Bureau of Statistics, "Statistical abstract," Uganda Bureau of Statistics, Kampala2017.

[4] Global Burden of Collaborative Disease Network, "Global Burden of Disease Study 2016 (GBD 2016) Results," Institute for Health Metrics and Evaluation (IHME), Seattle. Available: http://ghdx.healthdata.org/gbd-results-tool2017.

[5] Ministry of Health, "Family Planning 2020 Commitment," Kampala. Available: http://www.familyplanning2020.org/entities/802017.

[6] Ministry of Health, "Comprehensive EPI Multi-Year Plan (2016- 2020)," Government of Uganda, Kampala, 2016.

[7] Ministry of Health, "Annual Health Sector Performance Report," Government of Uganda2018.

[8] Save the Children, "State of the World's Mothers Report 2015," Save the Children, London, United Kingdom, 2015.

[9] World Bank. Uganda Poverty Assessment: 2016: Fact Sheet [Online].

[10] MCS Program, "Uganda country summary," Available: https://www.mcsprogram.org/wpcontent/uploads/2017/04/Uganda-Country-Summary-March-2017.pdf2017.

[11] Ministry of Health, "National Health Accounts: Financial Years 2012/13 \& 2013/14," Government of Uganda, Kampala, 2015.

[12] Ministry of Health, "National Health Accounts 2015/16," Government of Uganda, Kampala2017.

[13] GAVI, "Gavi Full Country Evaluations: 2016 Dissemination Report," IHME, Seattle, WA2017. 
[14] IHME, "Assessing Facility Capacity, Costs of Care, and Patient Perspectives," University of Washington, Seattle: Available: https://www.healthdata.org/sites/default/files/files/policy_report/2014/ABCE/Uganda/ABCE_ Uganda full report 2014.pdf2014.

[15] T. Dmytraczenko, M. McEuen, and A. Levin, "Costs of Maternal Health Care Services in Masaka District, Uganda. Special Initiatives Report 16," USAID, Washington DC, 1999.

[16] S. Nam, "Final Evaluation of the Figo Saving Mothers and Newborns Project in Uganda," Options. Available: $\quad$ https://www.figo.org/sites/default/files/uploads/projectpublications/SMN/Uganda_3.pdf 2011.

[17] Uganda Bureau of Statistics and ICF, "Uganda Demographic and Health Survey 2016: Key Indicators Report," Uganda Bureau of Statistics (UBOS) and ICF, Kampala, Uganda and Rockville, Maryland, USA, 2017.

[18] The Partnership for Maternal Newborn \& Child Health, "Maternal and Child Health: Uganda," Available:

https://www.who.int/pmnch/media/membernews/2011/ugandabackgroundpaper.pdf2012.

[19] K. Xu, A. Soucat, J. Kutzin, C. Brindley, N. V. Maele, H. Touré, et al., "Public Spending on Health: A Closer Look at Global Trends," World Health Organization, Geneva(WHO/HIS/HGF/HFWorkingPaper/18.3). License: CC BY-NC-SA 3.0 IGO, 2018.

[20] WHO, "Sustainable health financing, universal coverage and social health insurance. World Health Assembly Resolution WHA58.33," World Health Organization, Geneva, 2005.

[21] WHO, "Domestic resource mobilization for sustainable financing for health in Africa African Region. Working Paper prepared by the WHO Regional Office for Africa," World Health Organization, Geneva, 2017.

[22] K. Xu, D. B. Evans, G. Carrin, and A. M. Aguilar-Rivera, "Designing health financing systems to reduce catastrophic health expenditure," World Health Organization, Geneva, 2005.

[23] K. Xu, D. B. Evans, K. Kawabata, R. Zeramdini, J. Klavus, and C. J. Murray, "Household catastrophic health expenditure: a multicountry analysis," Lancet, vol. 362, no. 9378, pp. 1117, Jul 12, 2003.

[24] W. Van Damme, L. Van Leemput, I. Por, W. Hardeman, and B. Meessen, "Out-of-pocket health expenditure and debt in poor households: evidence from Cambodia," Trop Med Int Health, vol. 9, no. 2, pp. 273-80, Feb 2004.

[25] A. Leive and K. Xu, "Coping with out-of-pocket health payments: empirical evidence from 15 African countries," Bull World Health Organ, vol. 86, no. 11, pp. 849-856, Nov 2008.

[26] O. Galarraga, S. G. Sosa-Rubi, A. Salinas-Rodriguez, and S. Sesma-Vazquez, "Health insurance for the poor: impact on catastrophic and out-of-pocket health expenditures in Mexico," Eur $J$ Health Econ, vol. 11, no. 5, pp. 437-47, Oct 2010.

[27] T. Bright, L. Felix, H. Kuper, and S. Polack, "A systematic review of strategies to increase access to health services among children in low and middle-income countries," BMC Health Serv Res, vol. 17, no. 1, p. 252, Apr 5, 2017.

[28] W. B. Asea, "Combating political and bureaucratic corruption in Uganda: Colossal challenges for the church and the citizens," HTS Teologiese Studies/Theological Studies, vol. 74, no. 2, 2018. 
[29] R. Flanary and W. David, "The state of corruption: A case study of Uganda," Third World Quarterly, vol. 20, no. 3, pp. 515-536, 1999.

[30] J. M. Kewaza, "Fighting corruption in Uganda: Despite small gains, citizens pessimistic about their role," Afrobarometer Dispatch2016, vol. No. 77 Available: http://afrobarometer.org/sites/default/files/publications/Dispatches/ab_r6_dispatchno77_ugand a corruption.pdf.

[31] M. Martini, "Uganda: Overview of corruption and anti-corruption," Transparency International, Available:

https://knowledgehub.transparency.org/assets/uploads/helpdesk/379_Uganda_Overview_of_c orruption_and_anticorruption.pdf2013.

[32] S. Leiderer, "Fungibility and the Choice of Aid Modalities: The Red Herring Revisited," United Nations University, Helsinki2012, vol. Working Paper No. 2012/68 Available: https://www.wider.unu.edu/sites/default/files/wp2012-068.pdf.

[33] S. Devarajan and V. Swaroop, "The Implications of Foreign Aid Fungibility for Development Assistance," Development Research Group, World Bank, Washington, DC, 1998.

[34] R. Atuhaire and W. Kaberuka, "Factors Contributing to Maternal Mortality in Uganda," African Journal of Economic Review, vol. IV, no. 2, pp. 43 - 57, 2016. 